\title{
CRITÉRIOS DE SELEÇÃO DE MATERIAIS TÊXTEIS PARA PRODUTOS DO VESTUÁRIO
}

Leile Naomy Clemente Komatsu

Universidade Estadual de Londrina

leile_clemente@hotmail.com

Marcela Almeida Brasil

Universidade Estadual de Londrina

marcelaabrasil@gmail.com

Patrícia de Mello Souza

Universidade Estadual de Londrina

Departamento de Design

patriciademellosouza@gmail.com

Resumo: A pesquisa desenvolvida neste artigo visa definir critérios para orientar a seleção de materiais têxteis mais adequados para o desenvolvimento de produtos do vestuário, bem como estudar o método de Winifred Aldrich para aplicá-lo na avaliação por profissionais da área. A escolha correta deve ocorrer desde o início da concepção do produto, para que não acarretem retrabalhos e desvios do que foi planejado. Diferentes características presentes nos diversos materiais têxteis disponíveis no mercado podem interferir no caimento desejado, o que altera diretamente a proposta de produto desenvolvida pelo designer. Dessa forma, entendese que quando se trata de caimento, é muito importante estudar métodos de averiguação para que o efeito produzido pelo tecido seja aquele requerido pelo projeto, de forma a efetivar a construção do produto exatamente conforme projetado. Para tanto, estudou-se o método de Aldrich (2007) para viabilizar o desenvolvimento desta pesquisa. Este método traz procedimentos simples e práticos, que estão ao alcance de alunos e profissionais que não possuem acesso a avançados recursos tecnológicos para a medição de determinadas características dos materiais que influenciam no seu comportamento, entre estas, a drapeabilidade, a distorção e o peso. A pesquisa é de cunho exploratório e descritivo, com base em levantamento de dados bibliográficos, além do estudo experimental do método de Aldrich, posteriormente executado pelos alunos do $3^{\circ}$ ano do Curso de Design de Moda da Universidade Estadual de Londrina na disciplina de Laboratório da Forma Avançada. A modelagem tridimensional foi a ferramenta utilizada para possibilitar os experimentos, tanto na fase de viabilização de produto quanto na de acompanhamento de processo e avaliação de resultados, nas quais utilizou-se manequins na escala de 1:2. Dessa forma, confeccionou-se diferentes peças do vestuário, sendo que cada qual foi materializada mais de uma vez usando tecidos com 
propriedades variadas entre si. Primeiramente, procedeu-se às análises de drapeabilidade, distorção e peso conforme procedimentos propostos pela metodologia aplicada e posteriormente, com as peças confeccionadas, foi possível constatar e analisar as diferenças de caimento. Tal análise, documentada através de imagens, realizou-se de maneira subjetiva por meio de observação criteriosa dos materiais considerando os produtos vestidos nos manequins. Elaboraram-se tabelas para melhor visualização e comparação dos dados. Dessa forma comprovou-se que o conhecimento dessas ferramentas simples de análise, permite que o profissional da área de Design de Moda otimize seus projetos no que diz respeito à seleção de materiais com caimento adequado aos produtos propostos.

Palavras-chave: Design de moda; avaliação têxtil; caimento; modelagem tridimensional

\section{REFERÊNCIA}

ALDRICH, Winifred. Fabric, form and flat pattern cutting. New York: Blackwell, 2007.

LERMA, Beatrice; DE GIORGI, Claudia; ALLIONE, Cristina. Design e materiali: sensorialità_sostenibilità_progetto. Milano: Francoangeli, 2011.

SOUZA, Patrícia de Mello. Estratégias de construção para estruturas têxteis vestíveis. 2013. Tese (Doutorado em Design) - Faculdade de Arquitetura, Artes e Comunicação, Universidade Estadual Paulista, Bauru, 2013 
